\title{
ASSESSMENT OF FLOODING IN THE DOWNSTREAM AREA OF KIEN GIANG RIVER BASIN, QUANG BINH PROVINCE BASED ON USING THE MATHEMATICAL MODEL AND REMOTE SENSING TECHNIQUE
}

\author{
Dao Dinh Cham*, Nguyen Quang Minh, Nguyen Thai Son, Dao Thi Thao
}

Institute of Geography, VAST

*E-mail: chamvdl@gmail.com

Received: 22-6-2017

\begin{abstract}
Floods frequently occur in the central region in general and in Quang Binh province in particular, including the Kien Giang river basin. In recent years, due to the effects of global climate change and socio-economic development, natural disasters and floods are increasing and threatening the lives of people. This affects the socio-economic development of Quang Binh province. This paper presents the results of a study on the flooding and flooding levels of some typical floods in the downstream area of Kien Giang river, Quang Binh province based on the combination of using MIKEFLOOD model with remote sensing. This is one of the modern research methods that are quite useful in simulating, calculating and forecasting natural disasters occurring in coastal estuaries including floods. Combined use of these two methods yielded, quite accurate and similar results in calculating the flood level and inundation in the Kien Giang river basin. The authors have applied the MIKEFLOOD model to simulate the continuous evolution of inundation processes combined with remote sensing technology to compare and verify the calculation results of the model at the occurrence time of typical floods from 1999 up to now in the study area. The results of this article are the basis for warning and suggesting some measures to prevent flooding before the occurrence of heavy rains in Kien Giang river basin.
\end{abstract}

Keywords: MIKE, remote sensing, shoreline separation, landsat, inundation, Kien Giang river.

\section{INTRODUCTION}

Flooding is one of the major problems in the world and in Vietnam. Flood disaster is one of the natural disasters that encompass a large area.

Floods occurring in central river basins in general and Kien Giang river basin in particular are one of the most frequent natural disasters that threaten people's lives as well as socioeconomic development in the region and Quang Binh province.

Kien Giang river is the confluence of many rivers and streams, with a basin area of $2,650 \mathrm{~km}^{2}$, located in the depression of the Central Coast (fig. 1). The basin is severely divided, so the river network develops with a river network density of $0.84 \mathrm{~km} / \mathrm{km}^{2}$. The downstream area of the river is prone to flooding during rainy season. Every year, the area is always affected by the floods, resulting in economic, political, cultural and social damages in the area and threatening Dong Hoi city [1].

In the late twentieth and early XXI centuries, natural disasters and floods have occurred continuously in Kien Giang river basin. In particular, the historic floods in November 1999 and December 1999, October 2011, October 2013 and May, June 2016 have left hundreds of dead and missing, smothering thousands of houses, crops, with estimated losses of trillions 
VND. Floods have caused serious consequences, thousands of households have to move from landslide or flood areas, environmental ecosystems in coastal areas of estuaries are severely degraded [2].

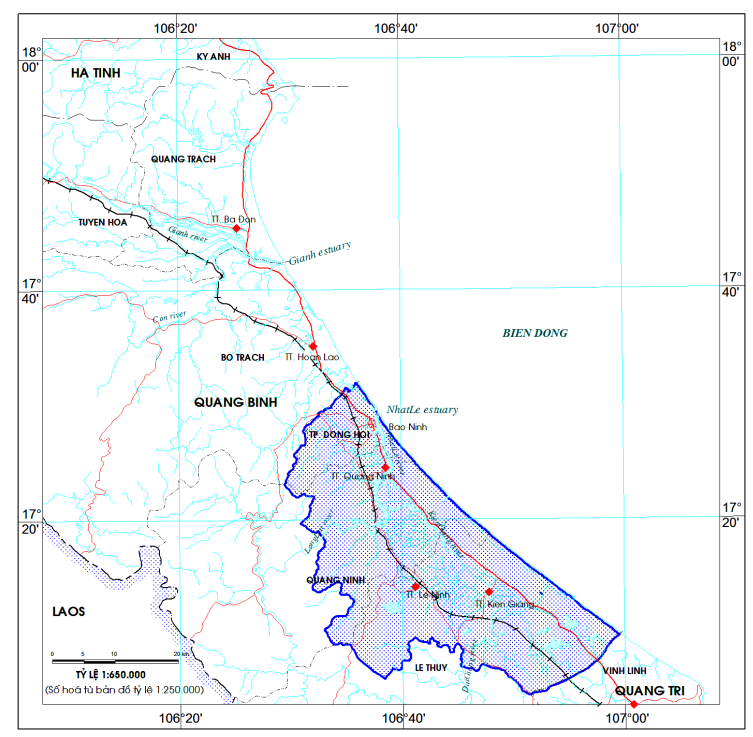

Fig. 1. Study area

This article introduces a method of assessing and simulating some typical flood events in Kien Giang river basin by combining mathematical model and remote sensing technology and geographic information system. The simultaneous use of these methods produces the best results in evaluating flood events compared to previous studies. The results of this study will be the basis for warning and flood prevention planning. In addition, they are a good reference for local decision-makers.

\section{METHODOLOGY}

\section{Statistical methods}

The collected data focus on meteorological, hydrologic, topographic, geological, socioeconomic data, current status of works in the basin, upstream reservoir operation process. Documentation is carried out according to process, norms (if any) and scientifically stored. The methods of synthesis, statistics, analysis, processing of existing basic data, data for research are used to calculate the study area.

\section{The mathematical modeling method}

This is a very important and effective method to implement the research topic. Based on the results obtained in the research on the basis of methodology, $\mathrm{PhD}$ students will establish or select appropriate modern mathematical models to calculate and simulate hydrodynamics, flood events. The object, the research problem are very complex; therefore, the tools, calculation software must be strong enough. At present, with the development of science that enables research to be very effective, is the mathematical modeling toolkit. Depending on the purpose of the study, one, two and three-dimensional numerical models will be suitable for application. Study on synthesis of flow in the catchment from rain, regulation of the lake often uses the models (MIKE11, NAM, HEC-RESSIM, HECHMS...). Hydraulic study of river systems uses 1 and 2-dimensional models (MIKE 11-ST, HEC-RAS, SOBEK...). River basin and river estuary research often uses 2 and 3-dimensional models as these models will simulate the field dynamics of the study area (MIKEFLOOD, DELFT3D, EFDC...). The selection and comparison of computational models should be carried out to produce accurate calibration results for the study area. The mathematical model helps us overlay information in the study area continuously over time to simulate the state and predict the change of natural conditions.

MIKEFLOOD is one of modules in MIKE package. It is integrated from 1-D flood modeling (MIKE11) and 2-D surface flow (MIKE21) to calculate unsteady flow hydraulics. The simulation results from this module have been verified in many basins in the world. In this study, MIKEFLOOD combined with Geographic Information System (GIS) is selected.

To compute the hydraulic boundaries, MIKE11HD has applied the NAM model. NAM is the abbreviation of the Danish (Nedbor - Astromnings - Model) which means precipitation - runoff flow. This model was originally developed by the Department of Hydrodynamics and Water Resources at the 
Technical University of Denmark (Nielsen and Hansen, (1973)). This is a conceptual model, describing the physical characteristics of the basin, on the basis of which it calculates rainfall flows. NAM is the conceptual hydrological model with concentration parameter. Its parameter and variables present the mean values for the entire basin. Several model parameters can be evaluated from physical characteristics of the basin but the result indicators must be obtained by comparing the calculated flow and the measured actual flow (fig. 2).

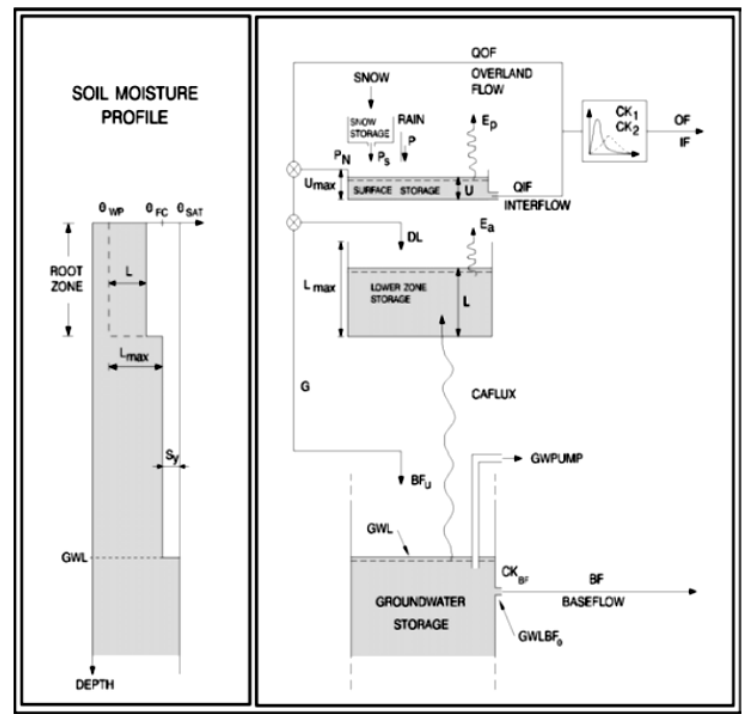

Fig. 2. The structure of NAM rainfall-runoff model

\section{Theoretical background of MIKE11HD model [5]}

Hydraulic equation: MIKE11HD employs full dynamic description for solving equations for conserving kinetic energy and integrating vertically (Saint Venant equations).

$$
\begin{gathered}
\frac{\partial Q}{\partial x}+\frac{\partial A}{\partial t}=q \\
\frac{\partial Q}{\partial t}+\frac{\partial}{\partial x}\left(\alpha \frac{Q^{2}}{A}\right)+g A \frac{\partial h}{\partial x}+\frac{g Q|Q|}{C^{2} A R}=0
\end{gathered}
$$

Where: $Q$ is the flow rate; $A$ is the area of the wet cross-section; $q$ is lateral flow; $h$ is the water depth; $C$ is the Chezy coefficient; $R$ is the hydraulic radius; $g$ is the gravitational acceleration.

The combined model MIKE21 is a dynamic modeling system that can be applied to estuaries, coastal areas, and rivers. The model includes the following modules: Flow module; Diffusion load module; Water quality module and ecology module; Modular transport of sludge, sand; Wave spectrum module.

\section{Theoretical background of MIKE21 model $[4,6]$}

MIKE21HD module mainly calculates unsteady flow in relatively shallow water. It takes into account the effects of tides, winds, atmospheric pressure, density variations (temperature and salinity), waves, tangles, and wet points on river banks. The equation of flow in this module is as follows:

Flow simulation equation.

The equation for simulating the flow of 2-dimensional flow is integrated from the vertical 3-dimensional equation showing the material conservation processes (1) and the momentum (2), (3) of the flow as follows:

$$
\frac{\partial \varsigma}{\partial t}+\frac{\partial p}{\partial x}+\frac{\partial q}{\partial y}=0
$$

$$
\begin{aligned}
& \frac{\partial p}{\partial t}+\frac{\partial}{\partial x}\left(\frac{p^{2}}{h}\right)+\frac{\partial}{\partial y}\left(\frac{p q}{h}\right)+g h \frac{\partial \varsigma}{\partial x} \\
& +g p \frac{\sqrt{p^{2}+q^{2}}}{C^{2} h^{2}}-\frac{1}{\rho_{w}}\left[\frac{\partial}{\partial x}\left(h \tau_{x x}\right)+\frac{\partial}{\partial y}\left(h \tau_{x y}\right)\right] \\
& -\Omega q-f V V_{x}+\frac{h}{\rho_{w}} \frac{\partial}{\partial x}\left(p_{a}\right)=0 \\
& \frac{\partial q}{\partial t}+\frac{\partial}{\partial y}\left(\frac{q^{2}}{h}\right)+\frac{\partial}{\partial x}\left(\frac{p q}{h}\right)+g h \frac{\partial \varsigma}{\partial y} \\
& +g p \frac{\sqrt{p^{2}+q^{2}}}{C^{2} h^{2}}-\frac{1}{\rho_{w}}\left[\frac{\partial}{\partial y}\left(h \tau_{y y}\right)+\frac{\partial}{\partial x}\left(h \tau_{x y}\right)\right] \\
& -\Omega p-f V V_{y}+\frac{h}{\rho_{w}} \frac{\partial}{\partial y}\left(p_{a}\right)=0
\end{aligned}
$$


In the equation symbols are used as follows: $h(x, y, t)$ - the water depth at point $(x, y)$ relative to zero level; $\varsigma(x, y, t)$ - water surface elevation relative to zero level; $p, q,(x, y, t)$ the flux density in $x$ and $y$ directions $\left(\mathrm{m}^{3} / \mathrm{s} / \mathrm{m}=\right.$ $(u h, v h) ;(u, v)$ - Average velocity in depth in the $\mathrm{x}$ and $\mathrm{y}$ directions; $C(x, y, t)$ - Chezy coefficient $\left(\mathrm{m}^{1 / 2} / \mathrm{s}\right) ; \quad g-\quad$ gravitational acceleration; $f(V)$ - wind friction coefficient; $V, V_{x}, V_{y}(x, y, t)$ - wind speed in $x$ and $y$ directions; $\Omega(x, y)$ - Coriolis $\left(\mathrm{s}^{-1}\right) ; p_{q}(x, y, t)$ atmospheric pressure $\left(\mathrm{kg} / \mathrm{m} / \mathrm{s}^{2}\right) ; \quad \rho_{w}-$ water density $\left(\mathrm{kg} / \mathrm{m}^{3}\right) ; x, y$ - coordinates $(\mathrm{m}) ; t$ - time $(\mathrm{s}) ; \tau_{x x}, \tau_{x y}, \tau_{y y}-$ shear stress components.
The alternating direction implicit (ADI) approach and the double-precision (DS) algorithm for each directional matrix are used to solve the continuous-equation system and to preserve the flow of momentum.

Setting up MIKEFLOOD mathematical model for the study area

Input data.

Evaporation: Data at Dong Hoi meteorological station is used. Only Piche evaporation is available, therefore calculation of ETo (by Penman formula) is applied.

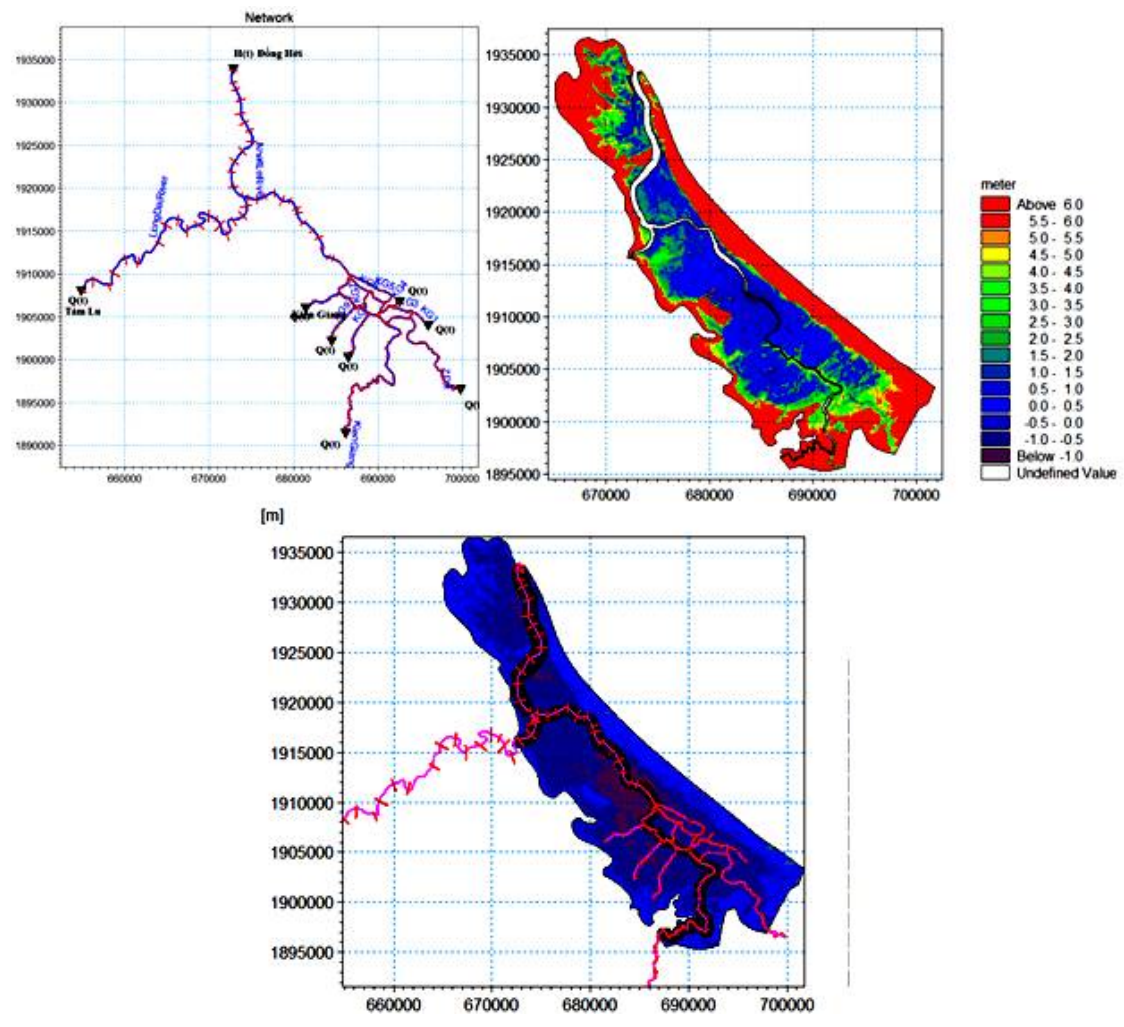

Fig. 3. Connecting NAM, MIKE1HD and MIKE21FM (MIKEFLOOD) models

Rainfall: Rainfall data is available at Kien Giang station (November 1999, November 2000, November 2015, Obtober 2016). (Source: General Department of Irrigation).

Discharge: The observed hourly flood level in 2016 is available at Kien Giang Station. Based on $\mathrm{Q} \sim \mathrm{H}$ curve at Kien Giang station, the hourly discharge in Obtober 2016 is obtained. Flood event in November 2015 is used for verification. After calibration and verification of parameters in NAM model, rainfall data in Dong Hoi station are used to simulate flood flows in November 1999 and November 2000, and these results are used as inputs for the MIKE11 HD model. 
Water level: Observed data at Dong Hoi Station (November 1999, November 2000).

Topological data: DEM in $30 \mathrm{~m}$ resolution is gridded in $10 \mathrm{~m}$ for MIKE21, and it is also used to create cross sections for MIKE11 model (fig. 3). DEM is created from topographical map at scale of 1:10,000. (Source: Institute of Geography).

\section{Remote Sensing and Geographic Information System (GIS)}

\section{Method of interpolation of waterways $[8,9]$}

This article uses a combination of NDWI and the ratio method used by the Green/NIR/Green image channel and the medium/Green/MIR because the ratio of Green/NIR is necessary to extract the soil from the plant and the Green/MIR ratio is necessary to separate vegetation and unused land.

In which, the NDWI (Normalized Differenced Water Index) is calculated according to Gao's formula [8] as follows:

$$
N D W I=\frac{B 4-B 5}{B 4+B 5}
$$

To separate the waterline on Landsat images, the authors used the Gonçalves formula [10]:

$$
\text { Shoreline }=\frac{B 2}{B 4} \times \frac{B 2}{B 5}
$$

In which: B2: Is the Green channel on the Landsat image (Band 2 for Landsat $5 \mathrm{TM}$, Band 3 for Landsat 8 OLI); B4: Red channel on Landsat image (Band 3 on Landsat 5 TM image, Channel 4 on Landsat 8 OLI image); B5: Infrared channel on Landsat image (Band 4 on Landsat 5 TM image, Channel 5 on Landsat 8 OLI image).

\section{Resolving clouds on Landsat image solving}

The Landsat image was studied by the Canadian Remote Sensing Center (Haze Optimized Transform) [10]. The HOT method is based on the fact that the bands in the wavelength range seen are highly correlated to the subjects in the sky shooting but vary in the degree of cloudiness of the gray value brother.
The unclouded areas of the scene are visually identified and used to identify the "inner row" of relations between bands with a variety of surface cover factors. The HOT algorithm is measured by the deviation of the orthogonal in the spectral domain of the visible wave, $B 1, B 3$ is the grayscale values of bands 1 (Blue) and 3 (Red). HOT is calculated by the following formula:

$$
H O T=B 1 \sin \theta-B 3 \cos \theta
$$

The angle $\theta$ is determined from the highly correlated pixel patterns (between $B 1$ and $B 3$ ) in the cloudless region of the scene. HOT values are calculated for each pixel then considered to be the spatial distribution of the cloud. A HOT photo mask will be used to eradicate haze at some points, even in some of the undetected photos with the naked eye. The adjustable gray level for each pixel is different between the lower limit of the histogram involved and the histogram of the pixels in the cloudless region. Excluding cloud cover can be determined not depending on the level of the original cloud. Although every pixel affected by haze is highlighted, only some can be calibrated.

\section{RESULTS AND CONCLUSION}

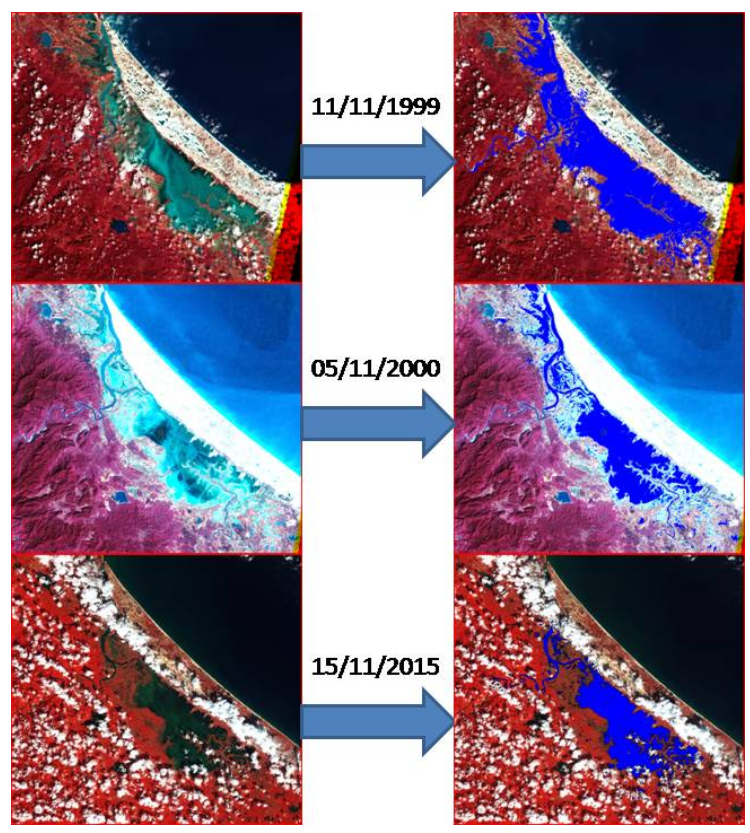

Fig. 4. Separation of water body by NDWI index from Kien Giang - Quang Binh river section 
After implementing the above method, the shoreline will be made in raster format, then the data will be transferred to GIS software to semi-automatic and the shoreline map will be completed. Applied to the Kien Giang basin the article uses the image of Landsat 5 TM with 2 scenes taken on November 11, 1999 and November 5, 2000 and Landsat 8 OLI taken on November 15, 2015 downloaded from the website: http://glovis.usgs.gov/ [9] (fig. 4).
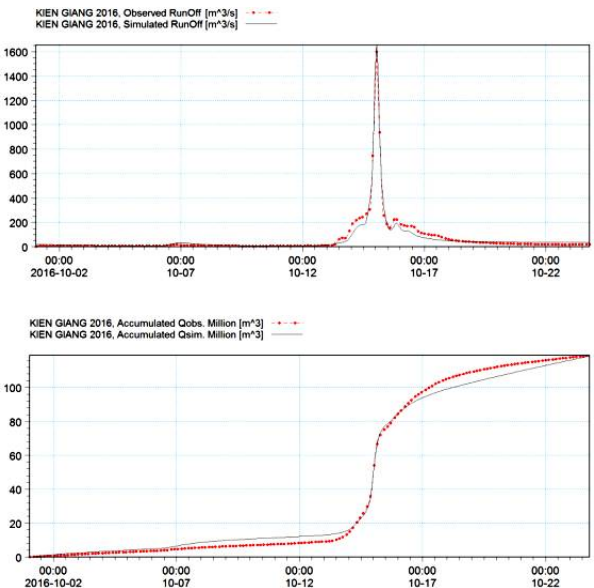

Flood event October 1 to November 23, 2016 KIENGIANG, Observed RunOff $\left[\mathrm{m}^{\wedge} 3 / \mathrm{s}\right]$
KIENGIANG, Simulated RunOff $\left[\mathrm{m}^{\wedge} / \mathrm{s}\right]$

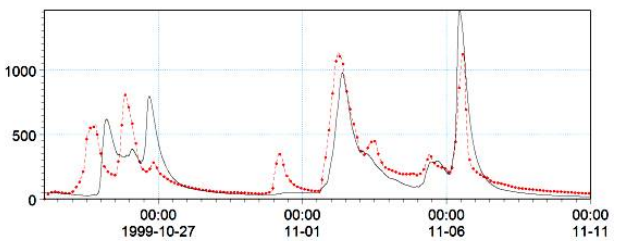

KIENGIANG, Accumulated Qobs. Million $\left[\mathrm{m}^{\wedge} 3\right]$
KIENGIANG, Accumulated Qsim. Million $\left[\mathrm{m}^{\wedge} 3\right]$

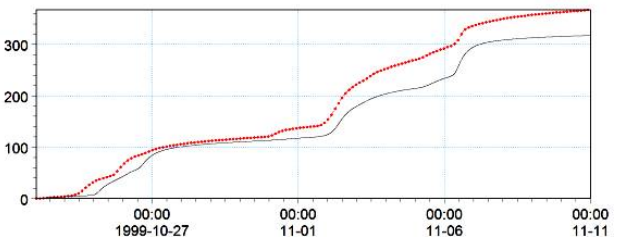

Flood event from November 1 to November 11, 1999
The result from MIKEFLOOD shows that the flow rate calculated from the MIKE11NAM model is in quite good agreement with observed discharge (fig. 5). NASH coefficient is very high $(98 \%$ - table 1$)$. The parameter set (table 2) therefore is used to simulate runoff for subsequent years which is used as boundary input for hydraulic modeling for routing flow in the river.
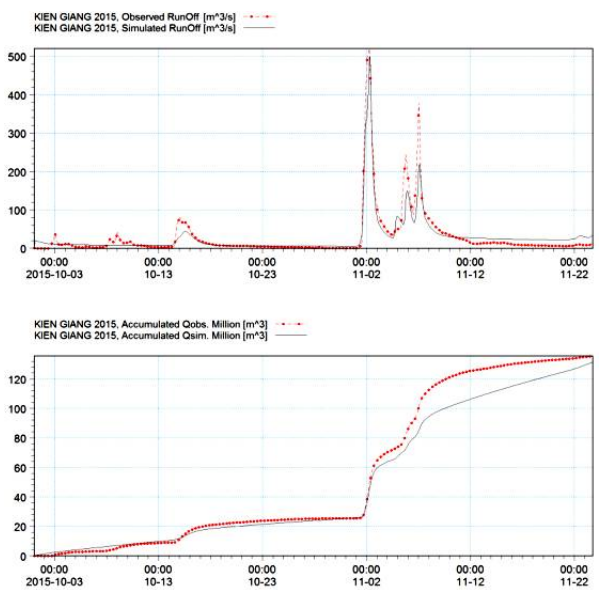

Flood event from October 1 to November 23, 2015 KIENGIANG, Observed RunOff $\left[\mathrm{m}^{\wedge} 3 / \mathrm{s}\right] \ldots$.
KIENGIANG, Simulated RunOff $\left[\mathrm{m}^{\wedge} 3 / \mathrm{s}\right]$

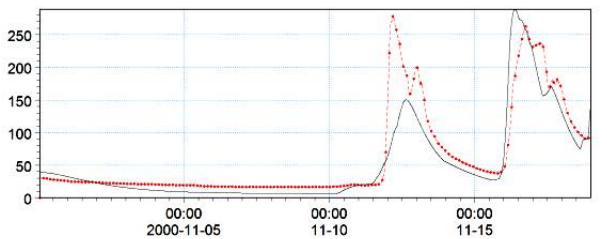
KIENGIANG, Accumulated Qobs. Million $\left[m^{\wedge} 33\right] \ldots$
KIENGIANG, Accumulated Qsim. Million $\left[m^{\wedge} 3\right]$

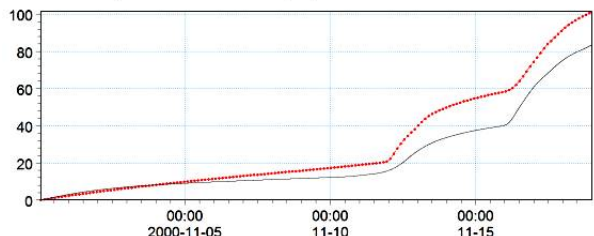

Flood event from November 1 to November 15, 2000

Fig. 5. Calibration and verification results of dischage at Kien Giang station

Table 1. Flood path selection for calibration and verification cases

\begin{tabular}{llll}
\hline & \multicolumn{1}{c}{ Time } & NASH \\
\cline { 4 - 4 } Calibration & from October 1 to November 23, 2016 & & 0.98 \\
& from October 1 to November 23, 2015 & & 0.89 \\
Verification & from November 1 to November 11, 1999 & & 0.87 \\
& from November 1 to November 15, 2000 & 0.78 \\
\hline
\end{tabular}


Dao Dinh Cham, Nguyen Quang Minh,...

Table 2. NAM model setting, flood event October 1 to November 23, 2016 at Kien Giang station

\begin{tabular}{|c|c|c|c|c|c|c|}
\hline Umax & Lmax & $\overline{\text { CQOF }}$ & $\overline{\text { CKIF }}$ & CK1,2 & TOF & $\overline{\text { TIF }}$ \\
\hline 12.6 & 101 & 0.35 & 550.1 & 11.8 & 0.36 & 0.501 \\
\hline
\end{tabular}

After calibration and verification, simulations of the floods on November 11, 1999 and November 1, 2000 are carried out to compare with Landsat 5 satellite image. The simulation result from the MIKEFLOOD and the processed image show a fairly similar inundation. The similarity is quite high in some communes such as Hong Thuy, Loc Thuy, Kien
Giang towns (fig. 6, 7, 8, 9, 10 and 11). An Thuy commune has the largest flooded area (more than 2,000 ha), and Hong Thuy commune has a deep flooding level (deeper than $3 \mathrm{~m}$ ). This is a low lying area so drainage is not easy. The area near My Trung dam is shrinking so floods are frequent (table 3, 4 and 5).
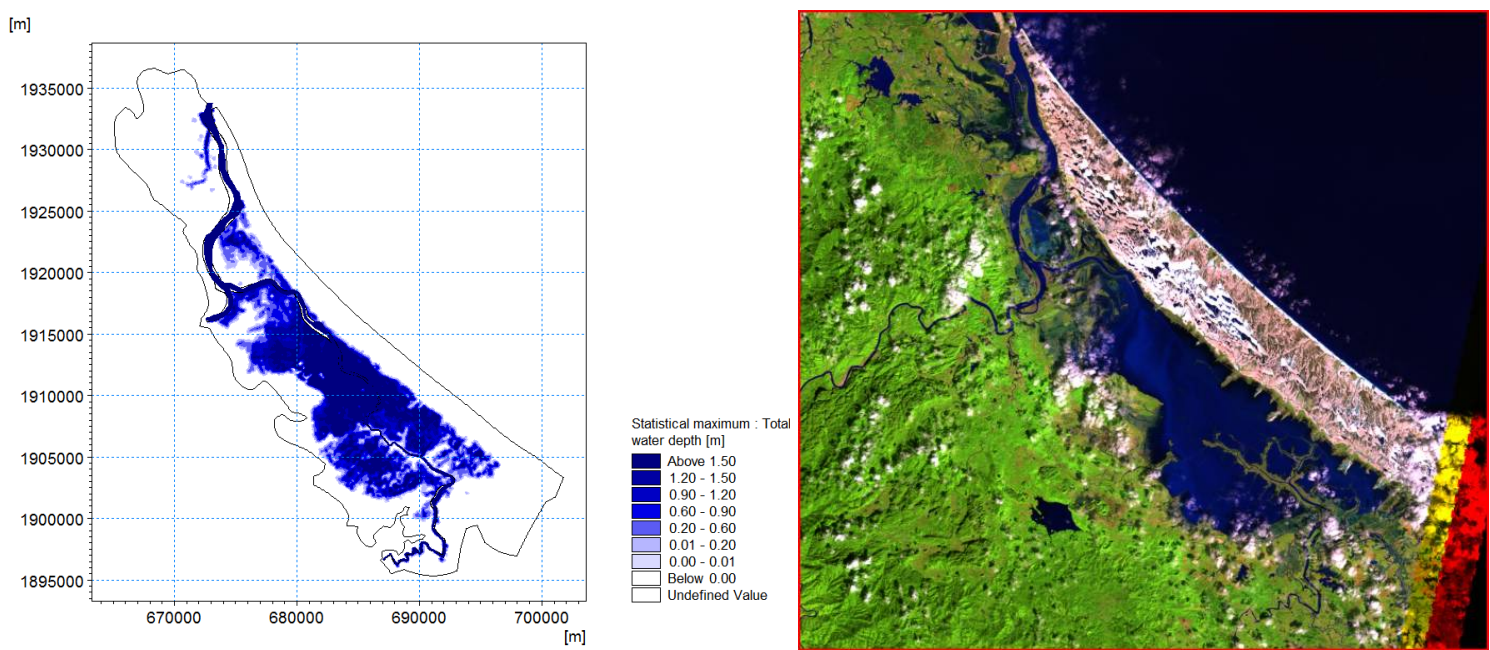

Fig. 6. Result of flooded area from the MIKEFLOOD model and Landsat 5 satellite imagery of flood November 11, 1999
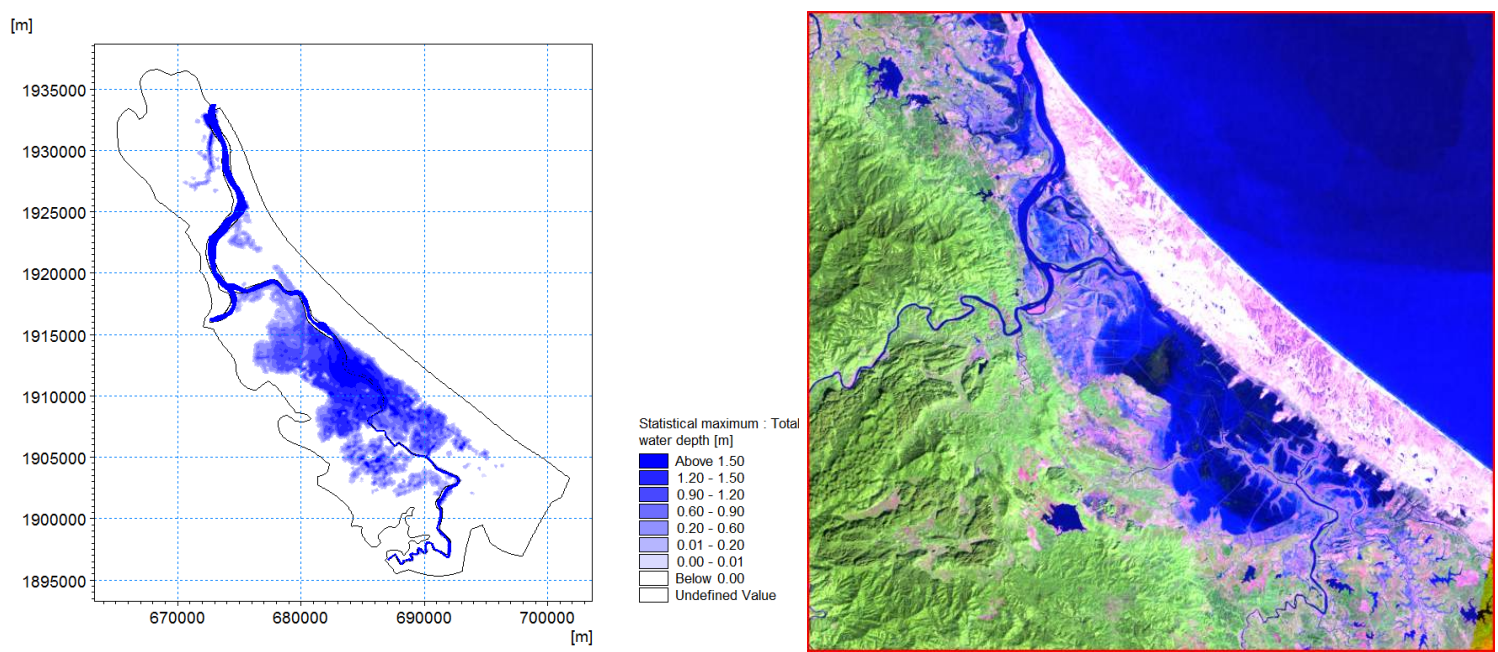

Fig. 7. Result of flooded area from the MIKEFLOOD model and Landsat 5 satellite imagery of flood November 5,2000 

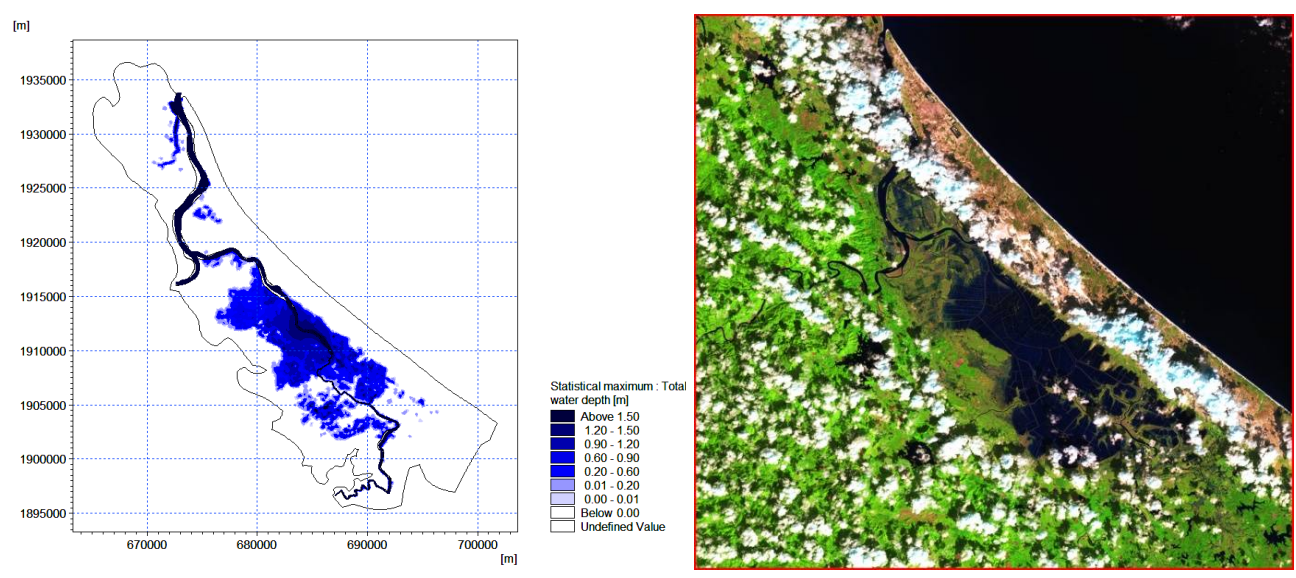

Fig. 8. Result of flooded area from the MIKEFLOOD model and Landsat 8 satellite imagery of flood November 15,2015

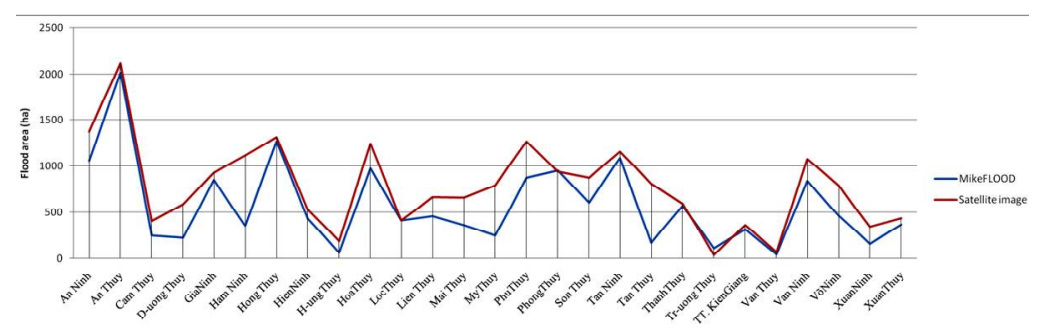

Fig. 9. Comparison of flooded area from the MIKEFLOOD model and satellite imagery of flood November 11, 1999

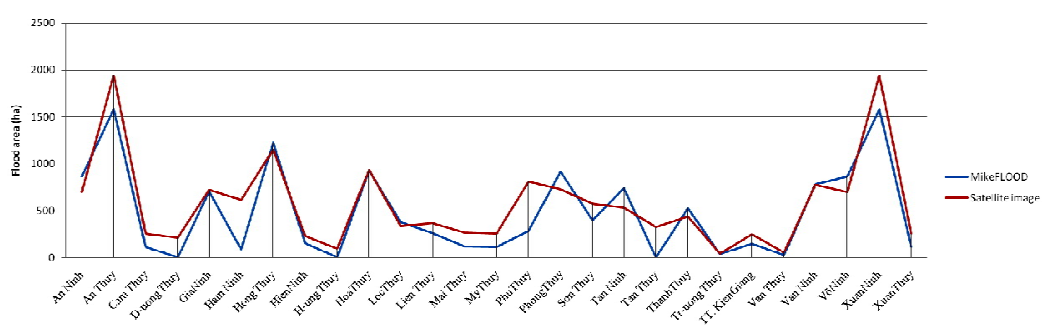

Fig. 10. Comparison of flooded area from the MIKEFLOOD model and satellite imagery of the flood on November 5, 2000

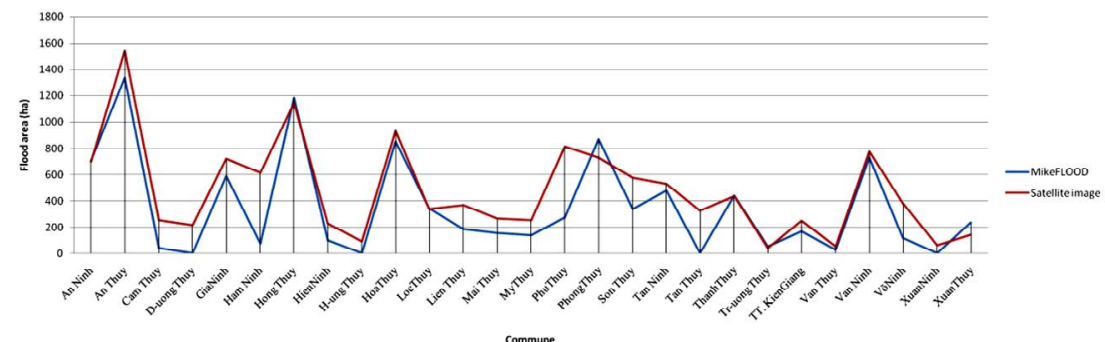

Fig. 11. Comparing the flooded area from the MIKEFLOOD model and the satellite imagery of the flood in November 15, 2015 
Dao Dinh Cham, Nguyen Quang Minh,...

Table 3. Flooded areas (ha) and flood levels (m) during flood on November 11, 1999

\begin{tabular}{|c|c|c|c|c|c|c|c|c|c|c|c|}
\hline \multirow{2}{*}{ Commune } & \multicolumn{10}{|c|}{ Flooded area by flood level from MIKEFLOOD model $(\mathrm{m})$} & \multirow{2}{*}{$\begin{array}{c}\begin{array}{c}\text { Flood area from } \\
\text { Satellite image }\end{array} \\
\text { Total (ha) }\end{array}$} \\
\hline & $0.1-0.5$ & $0.5-1$ & $1-1.5$ & $1.5-2$ & $2-2.5$ & $2.5-3$ & $3-3.5$ & $3.5-4$ & $4-4.5$ & Total (ha) & \\
\hline An Ninh & 147.6 & 182.0 & 521.0 & 207.2 & & & & & & 1057.8 & 1374.7 \\
\hline An Thuy & 152.7 & 302.1 & 444.8 & 734.3 & 333.9 & 33.7 & 6.4 & 2.8 & 1.3 & 2012.0 & 2112.4 \\
\hline Gia Ninh & 80.6 & 124.9 & 224.7 & 389.2 & 29.6 & 0.2 & & & & 849.3 & 928.0 \\
\hline Hong Thuy & 45.0 & 55.8 & 107.3 & 428.0 & 525.7 & 58.0 & 22.3 & 19.0 & 6.6 & 1267.7 & 1315.8 \\
\hline Hien Ninh & 110.3 & 151.5 & 144.3 & 23.8 & 0.7 & & & & & 430.6 & 534.2 \\
\hline Hoa Thuy & 42.7 & 90.2 & 128.1 & 420.4 & 292.9 & 0.1 & & & & 974.5 & 1246.0 \\
\hline Loc Thuy & 41.5 & 80.2 & 226.9 & 59.8 & 5.2 & 0.3 & & & & 414.0 & 415.9 \\
\hline Lien Thuy & 131.9 & 139.8 & 126.1 & 44.4 & 12.7 & 6.3 & 1.5 & & & 462.8 & 665.5 \\
\hline Mai Thuy & 102.1 & 76.5 & 72.6 & 59.5 & 37.5 & 7.7 & 2.3 & 0.9 & 0.8 & 359.9 & 661.6 \\
\hline My Thuy & 73.3 & 51.3 & 32.8 & 32.5 & 28.3 & 18.5 & 9.0 & 1.6 & 0.7 & 247.9 & 790.8 \\
\hline Phu Thuy & 162.1 & 307.3 & 264.1 & 118.2 & 21.7 & 1.7 & & & & 875.1 & 1271.3 \\
\hline Phong Thuy & 35.5 & 88.2 & 367.6 & 394.5 & 64.6 & 1.9 & & & & 952.3 & 939.5 \\
\hline Son Thuy & 133.5 & 107.1 & 111.3 & 222.0 & 34.2 & & & & & 608.1 & 871.9 \\
\hline Tan Ninh & 204.0 & 420.2 & 364.0 & 96.7 & & & & & & 1085.0 & 1158.6 \\
\hline Thanh Thuy & 57.2 & 73.1 & 141.5 & 268.1 & 32.9 & & & & & 572.9 & 595.6 \\
\hline Truong Thuy & 25.4 & 18.6 & 15.3 & 14.0 & 10.8 & 9.7 & 8.5 & 7.8 & 4.0 & 114.0 & 43.5 \\
\hline Kien Giang & 77.6 & 78.5 & 82.2 & 56.1 & 16.8 & 2.3 & 0.0 & & & 313.6 & 364.7 \\
\hline Van Thuy & 11.6 & 9.3 & 6.7 & 6.1 & 6.8 & 5.0 & 1.8 & 0.2 & & 47.4 & 74.7 \\
\hline Van Ninh & 65.0 & 75.3 & 204.6 & 471.0 & 24.8 & & & & & 840.7 & 1073.7 \\
\hline Vo Ninh & 210.1 & 164.9 & 58.0 & 24.0 & 3.6 & 2.1 & 1.4 & 0.7 & 0.2 & 465.1 & 794.9 \\
\hline XuanThuy & 81.2 & 128.3 & 86.7 & 36.9 & 18.5 & 9.8 & 2.7 & 0.2 & & 364.3 & 438.9 \\
\hline
\end{tabular}

Table 4. Flooded areas (ha) and flood levels (m) during flood on November 5, 2000

\begin{tabular}{|c|c|c|c|c|c|c|c|c|c|c|c|}
\hline \multirow{2}{*}{ Commune } & \multicolumn{10}{|c|}{ Flooded area by flood level from MIKEFLOOD model $(m)$} & \multirow{2}{*}{$\begin{array}{c}\begin{array}{c}\text { Flood area from } \\
\text { Satellite image }\end{array} \\
\text { Total (ha) } \\
\end{array}$} \\
\hline & $0.1-0.5$ & $0.5-1$ & $1-1.5$ & $1.5-2$ & $2-2.5$ & $2.5-3$ & $3-3.5$ & $3.5-4$ & $4-4.5$ & Total (ha) & \\
\hline An Ninh & 163.4 & 541.1 & 160.7 & & & & & & & 865.3 & 698.5 \\
\hline An Thuy & 349.4 & 399.0 & 623.7 & 188.4 & 13.6 & 3.6 & 1.5 & 1.0 & 0.9 & 1581.2 & 1940.7 \\
\hline Gia Ninh & 126.7 & 191.3 & 368.4 & 21.7 & 0.0 & & & & & 708.2 & 719.2 \\
\hline Hong Thuy & 53.0 & 107.6 & 461.8 & 501.2 & 52.3 & 22.5 & 17.8 & 3.6 & 2.0 & 1223.5 & 1145.1 \\
\hline Hien Ninh & 86.7 & 63.3 & 4.7 & 0.2 & & & & & & 154.9 & 230.0 \\
\hline Hoa Thuy & 93.1 & 140.5 & 484.4 & 211.0 & & & & & & 929.0 & 932.8 \\
\hline Loc Thuy & 84.1 & 230.1 & 60.2 & 5.6 & 0.3 & & & & & 380.2 & 337.9 \\
\hline Lien Thuy & 91.7 & 109.4 & 37.2 & 12.5 & 6.5 & 1.8 & & & & 259.0 & 367.4 \\
\hline Mai Thuy & 63.8 & 40.4 & 12.6 & 3.1 & 1.6 & 0.1 & & & & 121.6 & 267.0 \\
\hline My Thuy & 29.5 & 29.3 & 21.8 & 19.1 & 11.6 & 4.1 & 0.6 & 0.0 & & 115.9 & 252.8 \\
\hline Phu Thuy & 155.0 & 104.7 & 21.4 & 1.8 & & & & & & 282.9 & 812.7 \\
\hline Phong Thuy & 88.3 & 376.4 & 387.0 & 63.5 & 1.8 & & & & & 916.9 & 730.2 \\
\hline Son Thuy & 63.3 & 104.6 & 212.0 & 18.6 & & & & & & 398.6 & 576.1 \\
\hline Tan Ninh & 328.0 & 351.1 & 62.7 & & & & & & & 741.7 & 531.6 \\
\hline Thanh Thuy & 81.8 & 147.2 & 265.9 & 30.7 & & & & & & 525.6 & 438.5 \\
\hline Truong Thuy & 15.5 & 12.2 & 6.7 & 3.0 & 0.6 & 0.0 & & & & 38.0 & 41.9 \\
\hline Kien Giang & 65.1 & 43.0 & 23.5 & 13.3 & 3.2 & 0.2 & & & & 148.2 & 248.2 \\
\hline Van Thuy & 6.3 & 6.6 & 6.5 & 2.2 & 0.5 & 0.0 & & & & 22.2 & 55.9 \\
\hline Van Ninh & 83.5 & 245.9 & 444.5 & 10.8 & & & & & & 784.7 & 774.8 \\
\hline Vo Ninh & 163.4 & 541.1 & 160.7 & & & & & & & 865.3 & 698.5 \\
\hline Xuan Thuy & 68.2 & 33.8 & 9.2 & 3.6 & & & & & & 114.8 & 254.5 \\
\hline
\end{tabular}


Table 5. Flooded areas (ha) and flood levels (m) during flood on November 15, 2015

\begin{tabular}{|c|c|c|c|c|c|c|c|c|c|c|c|}
\hline \multirow[t]{2}{*}{ Commune } & \multicolumn{10}{|c|}{ Flooded area by flood level from MIKEFLOOD model $(\mathrm{m})$} & \multirow{2}{*}{$\begin{array}{c}\begin{array}{c}\text { Flood area from } \\
\text { Satellite image }\end{array} \\
\text { Total (ha) }\end{array}$} \\
\hline & $0.1-0.5$ & $0.5-1$ & $1-1.5$ & $1.5-2$ & $2-2.5$ & $2.5-3$ & $3-3.5$ & $3.5-4$ & $4-4.5$ & Total (ha) & \\
\hline An Ninh & 374.0 & 333.6 & 0.7 & & & & & & & 708.3 & 698.5 \\
\hline An Thuy & 333.7 & 503.2 & 455.6 & 34.7 & 5.9 & 2.0 & 1.2 & 1.1 & 0.6 & 1337.9 & 1940.7 \\
\hline Gia Ninh & 133.5 & 394.4 & 61.4 & 0.7 & & & & & & 589.9 & 719.2 \\
\hline Hong Thuy & 77.7 & 288.8 & 686.0 & 76.1 & 25.9 & 20.5 & 6.3 & 2.0 & 1.6 & 1185.9 & 1145.1 \\
\hline Hien Ninh & 74.6 & 22.0 & 2.2 & 0.2 & & & & & & 99.0 & 230.0 \\
\hline Hoa Thuy & 103.5 & 340.6 & 405.7 & 1.0 & & & & & & 850.9 & 932.8 \\
\hline Loc Thuy & 181.1 & 141.5 & 17.3 & 0.9 & 0.0 & & & & & 340.9 & 337.9 \\
\hline Lien Thuy & 102.5 & 56.6 & 11.4 & 5.9 & 4.9 & 2.4 & & & & 183.7 & 367.4 \\
\hline Mai Thuy & 67.3 & 52.0 & 27.7 & 4.3 & 1.9 & 0.6 & 0.1 & & & 154.1 & 267.0 \\
\hline My Thuy & 39.1 & 32.6 & 24.0 & 18.1 & 15.6 & 5.2 & 1.0 & 0.0 & & 135.5 & 252.8 \\
\hline Phu Thuy & 183.9 & 78.7 & 11.6 & 0.6 & & & & & & 274.8 & 812.7 \\
\hline Phong Thuy & 220.4 & 513.8 & 126.2 & 8.9 & 0.5 & & & & & 869.7 & 730.2 \\
\hline Son Thuy & 64.0 & 211.4 & 61.6 & & & & & & & 337.0 & 576.1 \\
\hline Tan Ninh & 305.1 & 172.4 & 0.4 & & & & & & & 477.9 & 531.6 \\
\hline Thanh Thuy & 96.3 & 262.3 & 82.4 & & & & & & & 440.9 & 438.5 \\
\hline Truong Thuy & 17.8 & 13.1 & 9.6 & 5.7 & 2.6 & 1.7 & 0.1 & & & 50.7 & 41.9 \\
\hline Kien Giang & 69.3 & 60.1 & 19.7 & 13.0 & 3.9 & 0.3 & & & & 166.3 & 248.2 \\
\hline VanThuy & 6.8 & 6.3 & 7.6 & 4.2 & 1.5 & 0.2 & & & & 26.7 & 55.9 \\
\hline Van Ninh & 156.7 & 476.5 & 96.9 & & & & & & & 730.1 & 774.8 \\
\hline Vo Ninh & 87.8 & 16.1 & 4.7 & 3.7 & 2.2 & 1.6 & 0.8 & 0.3 & & 117.1 & 381.3 \\
\hline Xuan Thuy & 132.2 & 59.5 & 18.3 & 12.5 & 9.1 & 2.1 & 0.3 & & & 234.0 & 143.4 \\
\hline
\end{tabular}

The simulation results from the model and remote sensing images can be converted to vector format (GIS shapefile) to calculate the flooding area and flooding level at each commune. The combination of these two methods shows that it is possible to accurately evaluate flooding in the study area. The mathematical model can help to predict flooding area and flooding level in detail while the remote sensing image shows the actual flooding visually.

Every year, Kien Giang river basin is affected by three to four storms of high intensity. As a result, the basin is regularly flooded, affecting the livelihood of local people.

The study has applied the MIKEFLOOD combined with Geographic Information System to calculate and simulate flood inundation in the downstream area of Kien Giang river. At the same time, remote sensing technology is used to analyse the situation at the time of flood in order to compare, and verify the calculation results from the mathematical model. The results from the two methods are quite similar. This result will be the scientific basis for making plan of flood prevention as well as of socio-economic development strategies for Quang Binh province.

Acknowledgments: This article is part of the research VAST06.03/15-16. The author of the article would like to thank the Vietnam Academy of Science and Technology for funding the implementation of this project.

\section{REFERENCES}

1. Nguyen Lap Dan, Nguyen Van $\mathrm{Cu}$, Dao Dinh Cham, 2007. Study on present situation and addressing causes on sedimentation on Nhat Le estuary - Quang Binh province, and solutions to prevent the sedimentation. Main report, Hanoi.

2. Nguyen Van $\mathrm{Cu}, 2000$. Some opinions on the flood on November 16, 1999 in Central reagion and recommendations for urgent solutions to repair damage after flooding. Reports on Conferences: Title of conference proceedings "Scientific and technological forecasting and applications in hydrometeorology", Volume 2, Hanoi.

3. https://www.mikepoweredbydhi.com/download/mike-2016. 
4. DHI, 2016. MIKEFLOOD: 1D-2D Modelling. User Manual.

5. DHI, 2016. MIKE 11-A Modeling System for Rivers and Channels. Reference Manual, Danish Hydraulic Institute, Horsholm, Denmark.

6. DHI, 2016. MIKE21 Hydrodynamic module. Scientific documentation.

7. Gao, B. C., 1996. NDWI-A normalized difference water index for remote sensing of vegetation liquid water from space. Remote sensing of environment, 58(3), 257-266.
8. Gonçalves, G., Duro, N., Sousa, E., Pinto, L., and Figueiredo, I., 2014. Detecting changes on coastal primary sand dunes using multi-temporal Landsat Imagery. SPIE Remote Sensing, 924420924420 .

9. Website: http://glovis.usgs.gov/

10. Guindon, B., and Zhang, Y., 2002. Robust Haze Reduction: An integral processing component in satellite-based land cover mapping. In Symposium on Geospatial Theory, Processing and Applications, Ottawa. 